\title{
Elevated endoplasmic reticulum stress reinforced immunosuppression in the tumor microenvironment via myeloid-derived suppressor cells
}

\author{
Bo-Ra Lee ${ }^{1, *}$, Sun-Young Chang ${ }^{2, *}$, Eun-Hye Hong ${ }^{1}$, Bo-Eun Kwon ${ }^{1}$, Hong Min Kim ${ }^{3}$,

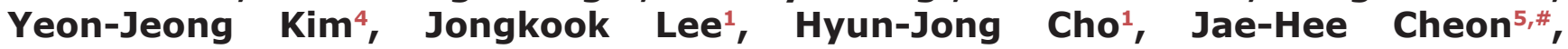 \\ Hyun-Jeong Ko, ${ }^{1, \#}$ \\ ${ }^{1}$ College of Pharmacy, Kangwon National University, Chuncheon 200-701, Korea \\ ${ }^{2}$ College of Pharmacy, Ajou University, Suwon 443-749, Korea \\ ${ }^{3}$ Department of Internal Medicine, Yonsei University Wonju College of Medicine, Wonju 220-701, Korea \\ ${ }^{4}$ College of Pharmacy, Inje University, Gimhae 621-749, Korea \\ ${ }^{5}$ Department of Internal Medicine and Institute of Gastroenterology, Yonsei University College of Medicine, Seoul \\ 120-752, Korea \\ *These authors contributed equally to this work \\ ${ }^{\#}$ Co-senior author \\ Correspondence to:
}

Hyun-Jeong Ko, e-mail: hjko@kangwon.ac.kr

Jae Hee Cheon, e-mail: geniushee@yuhs.ac

Keywords: cancer, ER stress, MDSC, immunosuppression, arginase-1

Received: August 04, $2014 \quad$ Accepted: October 11, 2014

Published: December 02, 2014

\section{ABSTRACT}

The role of endoplasmic reticulum (ER) stress in cancer has been studied in detail, and ER stress is known to increase tumor cell apoptosis, and thus, reduce tumor growth. However, in our study, persistent ER stress induced by multiple administrations of low-dose thapsigargin ( $\mathrm{Tg}$ ) accelerated tumor growth in mice. Tg-mediated ER stress increased the generation of $\mathrm{Ly} 6 \mathrm{G}^{+} \mathrm{CD} 11 \mathrm{~b}^{+}$myeloid cells, but did not alter anti-tumor effector $T$ cells. 4-Phenylbutyric acid (4-PBA), a chemical chaperone widely used as an ER stress reducer, attenuated Tg-induced myeloidderived suppressor cell (MDSC) expansion and tumor growth. Tg-mediated ER stress enhanced the immunosuppressive capacity of tumor-infiltrating MDSCs by increasing expression of ARG1, iNOS, and NOX2, although splenic MDSCs were not affected. Consistent with these results, 4-PBA restored the anti-tumor immune response by regulating inflammatory cytokines such as TNF-a and CXCL1/KC, and activated tumorinfiltrating $\mathrm{CDB}^{+} \mathrm{T}$ cells that were inhibited by $\mathrm{Tg}$-mediated ER stress. These results suggest that significant ER stress in a tumor-bearing host might induce tumor growth mediated by enhancement of MDSC-mediated suppression. Therefore, ER stress reducers such as 4-PBA could restore anti-tumor immunity by inhibiting suppressive MDSCs that are exacerbated by ER stress.

\section{INTRODUCTION}

Endoplasmic reticulum (ER) stress induction in cancer cells was once a promising strategy for efficiently inducing apoptosis of cancer cells, and several ER stress inducers, including thapsigargin (Tg), a sarcoplasmic/ endoplasmic $\mathrm{Ca}^{2+}$ ATPase inhibitor, were evaluated as anticancer drugs [1]. However, systemic administration of Tg induced non-selective apoptosis of host cells, including proliferative and quiescent cells [2], indicating that Tg might not be a good candidate anticancer drug for systemic administration. To overcome this limitation, targeted delivery of $\mathrm{Tg}$ has been evaluated in several murine cancer models $[1,3]$.

Although direct induction of apoptotic death in cancer cells may be critical for therapeutic antitumor 
effects, the tumor antigen-specific immune response against cancer cells has also been shown to efficiently inhibit tumor growth and eradicate residual tumor cells. In this regard, Tg-induced cell death could beneficially induce tumor-specific immunity following phagocytosis by dendritic cells [1]. We as well as other researchers have provided evidence supporting the combined therapeutic strategy of apoptosis induction by anticancer drugs and activation of the host immune system to remove residual cancer cells [4].

Myeloid-derived suppressor cells (MDSCs) are heterogeneous cell populations consisting of immature myeloid cells including immature macrophages, granulocytes, and dendritic cells. They are found in the blood, liver, and spleen, as well as in tumor cells $[5,6]$. More importantly, it has been suggested that tumorassociated suppressor cells, including MDSCs, inhibit the tumor-specific immune response, and inflammation caused by non-selective ER stress-mediated cell death could be associated with the induction of MDSC-like cells [7].

Here we investigated the effect of ER stress induced by treatment with $\mathrm{Tg}$, an ER stress inducer, on tumor growth. Surprisingly, systemic administration of Tg did not inhibit tumor growth, but instead, increased tumor growth. Although the role of ER stress in cancer has been studied in detail, the effects of ER stress on tumorassociated immune cells, especially MDSCs, have not been reported. Thus, we studied the effect of ER stress on MDSC generation after $\mathrm{Tg}$ administration in vivo. Interestingly, persistent and systemic ER stress induced by low dose and long-term administration of $\mathrm{Tg}$ increased MDSC generation in the spleens of tumor-bearing mice. More importantly, the immunosuppressive function of MDSCs, which is mediated by ARG1, iNOS, and NOX2, was also significantly increased by Tg treatment. Alleviation of ER stress by the administration of 4-PBA, a chemical chaperone used as an ER stress reducer [8], effectively restored the level of MDSCs and ameliorated their suppressive function in the tumor tissues, but had no effect on MDSCs in the spleen. Consistent with these results, accelerated tumor growth triggered by Tg was inhibited by 4-PBA treatment. These results suggest that ER stress in a tumor-bearing host might induce tumor growth by reinforcing the suppressive function of MDSCs within the tumor microenvironment.

\section{RESULTS}

\section{Tg treatment accelerated tumor growth in a mouse colon cancer model}

Previously, it was reported that induction of ER stress increased apoptosis of tumor cells in vitro, and therefore, reduced tumor growth in vivo [9]. $\mathrm{Tg}$ is a well-known ER stress inducer that inhibits sarcoplasmic/ endoplasmic $\mathrm{Ca}^{2+}$-ATPase $[1,10]$. Although $\mathrm{Tg}$ induces apoptosis in both proliferative and quiescent cells, it cannot be administered systemically because of host toxicity that is related to its non-selectivity [11]. However, several reports have shown a direct anticancer activity in vivo using a targeted $\mathrm{Tg}$ delivery system $[3,11]$. Thus, we assessed the anticancer activity of $\mathrm{Tg}$ in a murine colon cancer model. To reduce systemic and acute host toxicity, we adopted a low dose and long-term $\mathrm{Tg}$ treatment regimen. Groups of mice were subcutaneously administered $1 \times 10^{6}$ CT26 cells expressing HER2/neu (HER2/CT26 cells), and $100 \mu \mathrm{g} / \mathrm{kg}$ of Tg was intraperitoneally injected daily starting when tumor sizes reached $50-100 \mathrm{~mm}^{3}$. To our surprise, tumor growth was significantly increased in mice treated with $\mathrm{Tg}$ as compared with mice treated with the vehicle control (Figure 1A). When isolated tumor masses were analyzed, $\mathrm{Tg}$ treatment was significantly associated with increased tumor weight (Figure 1B). These results suggest that ER stress induction by systemic low dose Tg treatment can enhance tumor growth in vivo.

\section{Tg evoked ER stress and cell death in HER2/CT26 cells in vitro}

To verify ER stress in tumor and immune cells in the tumor microenvironment, we assessed the ER stress response and the subsequent cell death in HER2/CT26 cells and splenocytes $24 \mathrm{~h}$ after Tg treatment. We first confirmed the influence of $\mathrm{Tg}$ treatment on the ER stress response in HER2/CT26 tumor cells by measuring ER stress-induced $X B P 1 \mathrm{mRNA}$ splicing [12]. XBP1 slicing was detected when HER2/CT26 cells were treated with $100 \mathrm{nM}$ Tg (Figure 1C). Tg treatment mediated the ER stress response by transcriptional activation of several ER stress-related genes, including BiP, TNF- $\alpha$, Erdj4, CXCL1, and ATF4 (Figure 1D, Supplementary Figure 1).

Activation of the PERK-eIF2 $\alpha$ pathway is another characteristic of the ER stress response. Tg treatment increased protein expression of ATF4 and Chop and phosphorylation of eIF2 $\alpha$, PERK, and IKBalpha, suggesting activation of the PERK-eIF $2 \alpha$ pathway (Figure 1E). These results clearly show that Tg treatment induced ER stress in HER2/CT26 cells. We then evaluated whether ER stress induced by Tg treatment influences cell death. Tg treatment at concentrations lower than $10 \mathrm{nM}$ did not reduce cell viability in HER2/CT26 cells or splenocytes (Figures 1F and $1 \mathrm{G}$ ). However, concentrations of Tg greater than $100 \mathrm{nM}$ induced significant cell death in HER2/CT26 cells and splenocytes.

These results suggest that $\mathrm{Tg}$ treatment at high concentrations induces ER stress and cell death. In contrast, $10 \mathrm{nM} \mathrm{Tg}$ induced the ER stress response and increased transcriptional activation of Bip, protein expression of ATF4, and phosphorylation of PERK without inducing significant cytotoxicity. However, considered together with tumor growth observations, these 

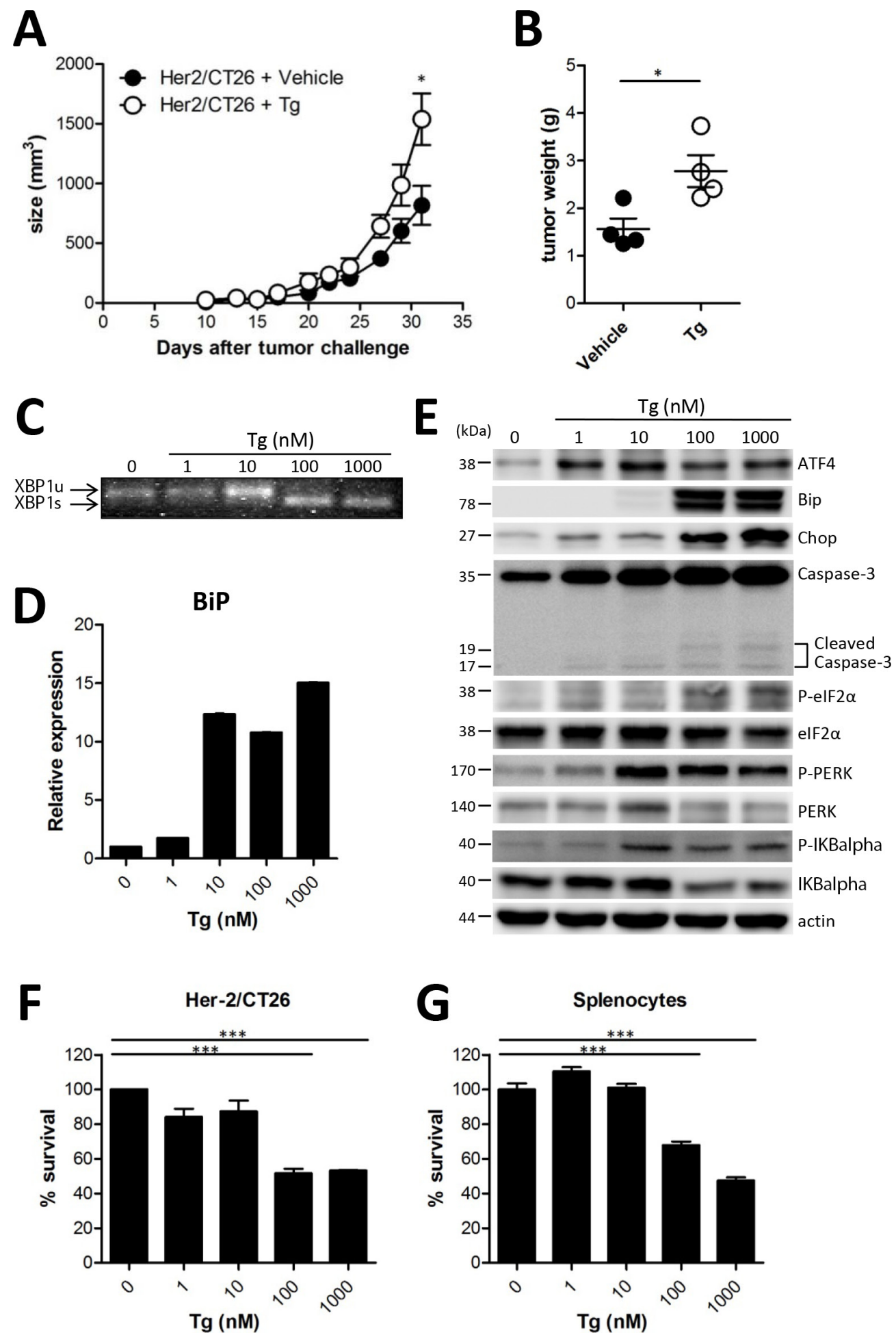

Figure 1: ER stress induced by Tg accelerated tumor growth. (A) BALB/c mice were injected s.c. with $10^{6} \mathrm{HER} 2 / \mathrm{CT} 26$ cells per mouse, and $100 \mu \mathrm{g} / \mathrm{kg}$ of Tg was administered i.p. every day before tumor challenge. Tumor growth was monitored ( $n=5$ ). (B) tumor weight at 4 weeks after HER2/CT26 injection $(n=4)$. Graphs show mean \pm SEM. ${ }^{*} p<0.05,{ }^{* * *} p<0.001$ compared with matched control group using the Student's $t$-test. (C) XBP 1 mRNA splicing in Tg-treated HER2/CT26 cells. (D) mRNA levels of BiP from Tg-treated HER2/ CT26 cells as measured by RT-qPCR. (E) immunoblot of Tg-treated HER2/CT26 cells for the PERK-eIF2 $\alpha$ branch. (F) HER2/CT26 cells were cultured with $\mathrm{Tg}$ for $24 \mathrm{~h}$ and cell viability was analyzed. (G) splenocytes were cultured with $\mathrm{Tg}$ for $24 \mathrm{~h}$ and cell viability was analyzed. ${ }^{* * *} p<0.001$ using one-way ANOVA with Tukey's post hoc test. 
effects could not explain the enhanced tumor growth cause by $\mathrm{Tg}$ treatment.

\section{Tg-mediated ER stress did not decrease the generation of antitumor effector $T$ cells}

Since Tg treatment significantly increased tumor growth in vivo (Figure 1A and 1B), we hypothesized that $\mathrm{Tg}$ might negatively influence the host immune system to reduce tumor protection. Therefore, we

analyzed $\mathrm{CD}^{+} \mathrm{T}$ cells, which are critical for the cytolytic elimination of cancer cells expressing tumor antigens. Although there was a significant decrease in the percentage of $\mathrm{CD}^{+} \mathrm{T}$ cells in the spleens of mice treated with $\mathrm{Tg}$ compared with vehicle-treated control mice (Figure 2A), the absolute number of splenic $\mathrm{CD}^{+}$ $\mathrm{T}$ cells was not changed (Figure $2 \mathrm{~B}$ ). In addition, memory $\mathrm{CD}^{+} \mathrm{T}$ cells expressing $\mathrm{Ly} 6 \mathrm{C}$, which are critical for successful antitumor activity [13], were not altered (Figure 2C). Next, we assessed whether Tg treatment
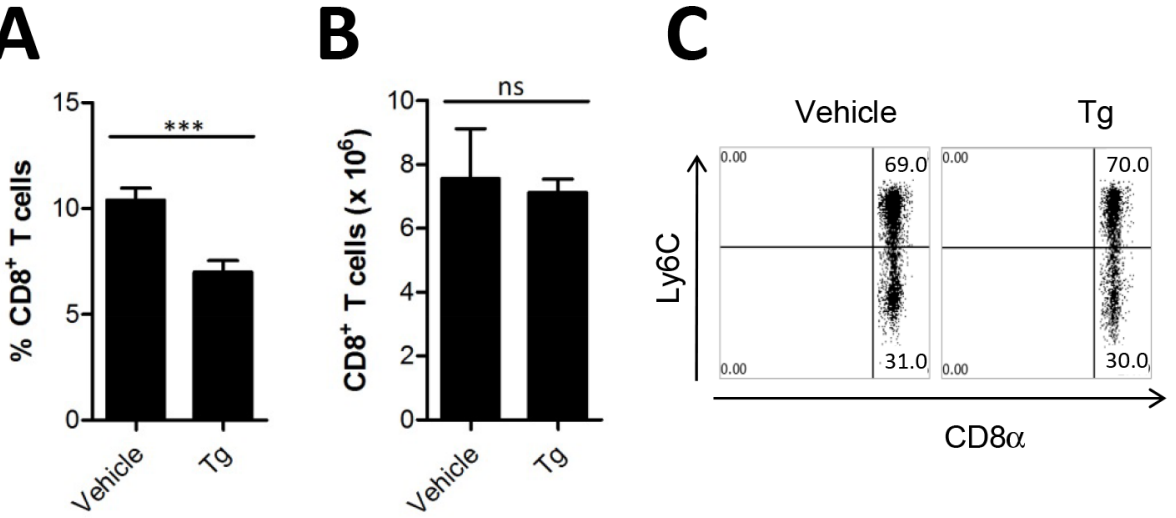

D
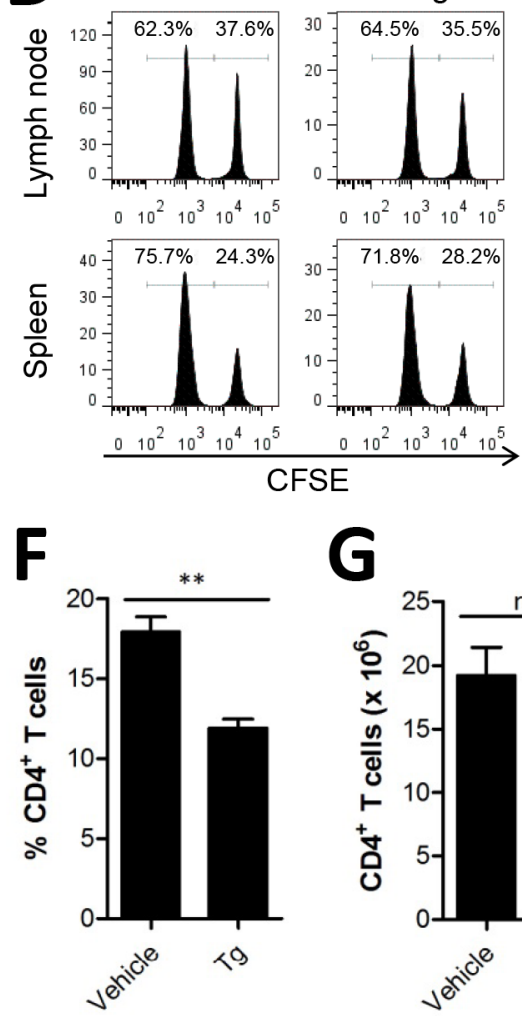

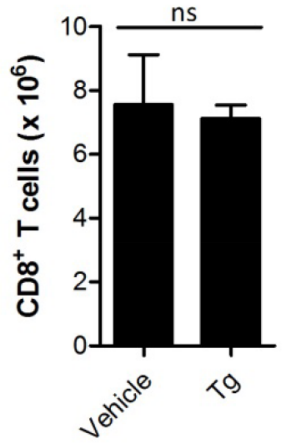

B $\mathrm{Tg}$
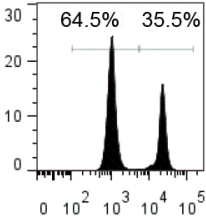

$\mathbf{G}$

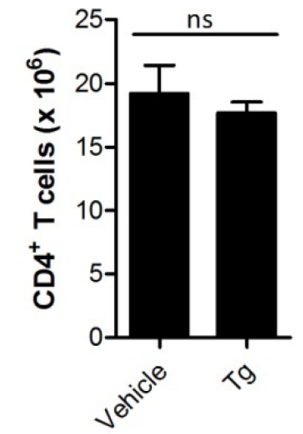

$\mathbf{E}$

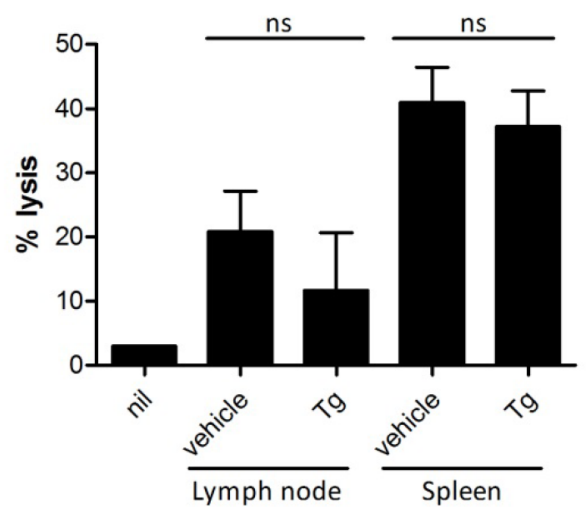

Figure 2: Tg-mediated ER stress did not alter anti-tumor effector T cells. (A-B), at 4 weeks after tumor challenge, the percentage and absolute number of $\mathrm{CD}^{+} \mathrm{T}$ cells in the spleen was assessed $(n=6)$. (C) percentages of $\mathrm{Ly}_{6 \mathrm{C}^{+} \mathrm{CD} 8}{ }^{+} \mathrm{T}$ cells in the splenocytes of HER2/ CT26 tumor-bearing mice. (D-E) specific lysis of hP63 (TYLPTNASL) peptide-loaded CFSE ${ }^{\text {high }}$ target cells was estimated by in vivo CTL from the spleen and lymph node of HER2/CT26 tumor-bearing mice $(n=6)$. (F-G) the percentage and absolute number of CD4 $4^{+}$T cells in the spleen of HER2/CT26-bearing mice $(n=7)$. Graphs show mean \pm SEM. ns, not significant, ${ }^{* *} p<0.01 ;{ }^{* * *} p<0.001$ compared with matched control group using the Student's t-test. 
reduces the tumor antigen-specific CTL response by in vivo CTL analysis. There was no significant decrease in the HER2/neu-specific CTL response after Tg treatment in tumor-draining LNs or in the spleen (Figures 2D and 2E). We also examined the population of $\mathrm{CD}^{+} \mathrm{T}$ cells. Similar to $\mathrm{CD}^{+} \mathrm{T}$ cells, the percentage of $\mathrm{CD}^{+} \mathrm{T}$ cells was decreased (Figure $2 \mathrm{~F}$ ), but there was no significant decrease in the number of $\mathrm{CD}^{+}$cells after $\mathrm{Tg}$ treatment (Figure 2G). These results indicate that the acceleration of tumor growth produced by $\mathrm{Tg}$ treatment might not be attributed to inhibition of antitumor effector $\mathrm{T}$ cells. In addition, there appeared to be no significant systemic impairment in the tumor antigen-specific cytotoxic activity of $\mathrm{CD}^{+} \mathrm{T}$ cells after $\mathrm{Tg}$ treatment.

\section{Tg-mediated ER stress increased Ly6G $^{+}$CD11b $^{+}$myeloid cells}

Because percentages of both $\mathrm{CD}^{+}$and $\mathrm{CD} 8^{+} \mathrm{T}$ cells were decreased in mice with larger tumor mass after Tg treatment, we hypothesized that immunosuppressive myeloid cells might have been expanded. Tg treatment significantly increased $\mathrm{Ly}_{6 \mathrm{G}}^{+} \mathrm{CD} 11 \mathrm{~b}^{+} \mathrm{MDSCs}$ in the spleen of HER2/CT26-bearing mice (16.4 $\pm 2.58 \%$,
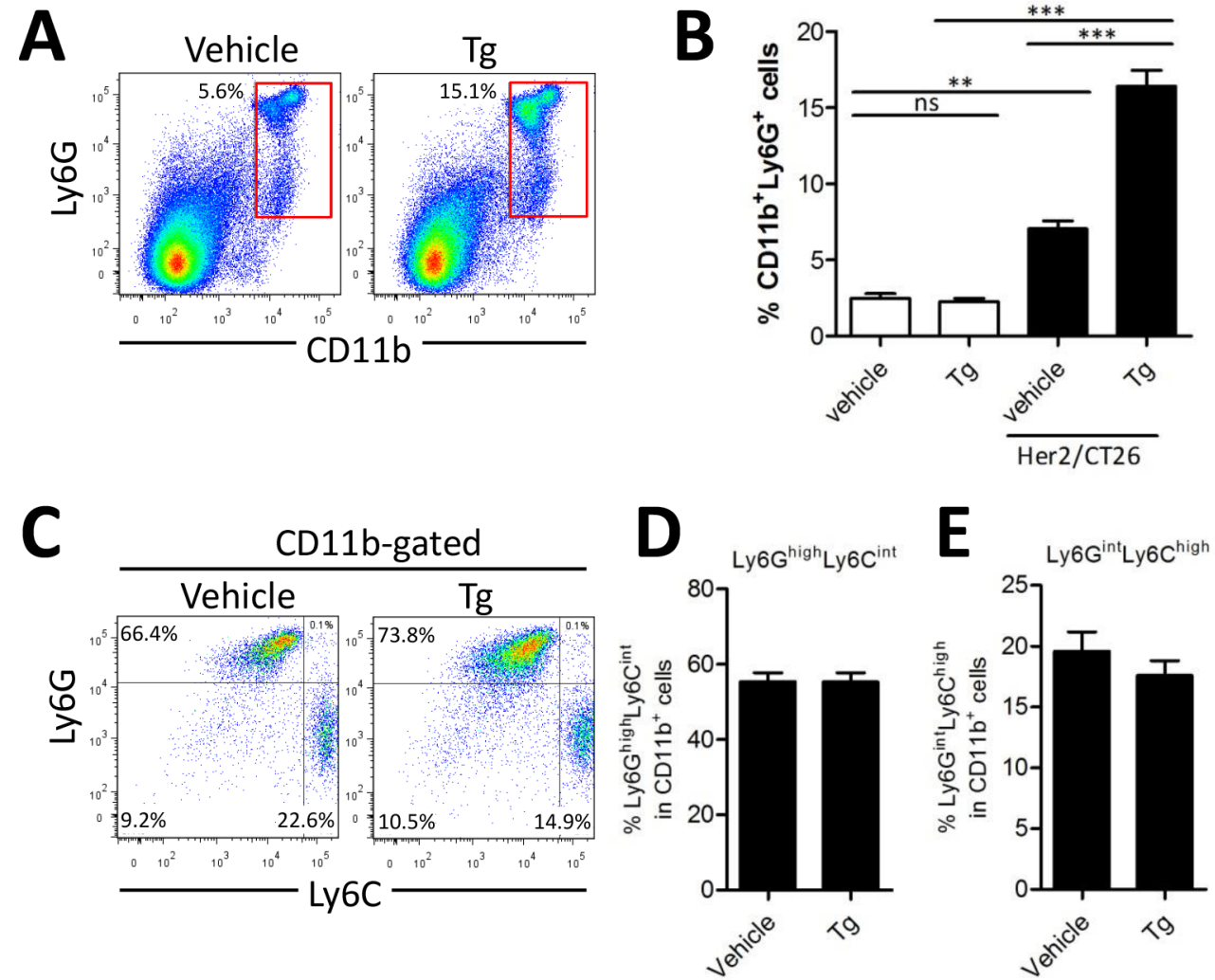

Figure 3: Tg-mediated ER stress increased the generation of $\mathbf{L y 6 G}^{+} \mathbf{C D}_{11} \mathbf{b}^{+}$myeloid cells. HER2/CT26 tumor-bearing mice were treated with $100 \mu \mathrm{g} / \mathrm{kg} \mathrm{Tg}$. At 4 weeks after tumor injection, splenic MDSC populations were analyzed. (A) splenic Ly6G ${ }^{+} \mathrm{CD}_{11 \mathrm{~b}^{+}}$ MDSCs. (B) summary graph showing the frequency of $\mathrm{Ly}_{6 \mathrm{G}} \mathrm{C}_{\mathrm{CD}} 11 \mathrm{~b}^{+}$cells $(n=6)$. ns, not significant, ${ }^{* * *} p<0.01,{ }^{* * * *} p<0.001$ compared with matched control group using one-way ANOVA. (C) MDSC sub-populations, monocyte-derived Ly6C $\mathrm{C}^{\text {high }}$ Ly6 $\mathrm{G}^{\text {int }}$ and granulocytederived Ly $6 \mathrm{C}^{\text {int }}$ Ly $6 \mathrm{G}^{\text {high }}$ among the $\mathrm{CD} 11 \mathrm{~b}^{+}$gated population. (D-E) summary graph of Ly $6 \mathrm{C}^{\text {high }}$ Ly $6 \mathrm{G}^{\text {int }}$ and Ly6C $\mathrm{C}^{\text {int }}$ Ly $6 \mathrm{G}^{\text {high }}$ cells among the

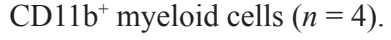


4-PBA was used to attenuate Tg-induced ER stress in tumor-bearing mice. 4-PBA is a chemical chaperone that can decrease the ER stress response and act as a histone deacetylase inhibitor [8]. When the growth of HER2/CT26 tumors was monitored, we found that the increased tumor growth induced by $\mathrm{Tg}$ treatment was dramatically inhibited by coadministration of 4-PBA (Figure 4A). In another tumor model using TC-1 cells,
Tg-induced tumor growth was also significantly inhibited by coadministration of 4-PBA (Figure 4B). In addition, the survival of Tg-treated mice was significantly increased by 4-PBA, compared to vehicle treatment group (Supplementary Figure 2).

To assess the potential of 4-PBA to reduce MDSC generation induced by ER stress, we examined splenic MDSCs. Treatment with $\mathrm{Tg}$ significantly increased

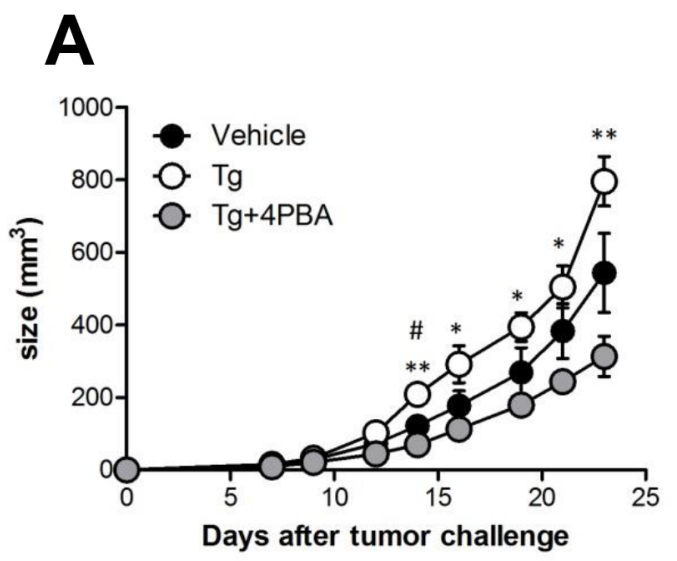

B
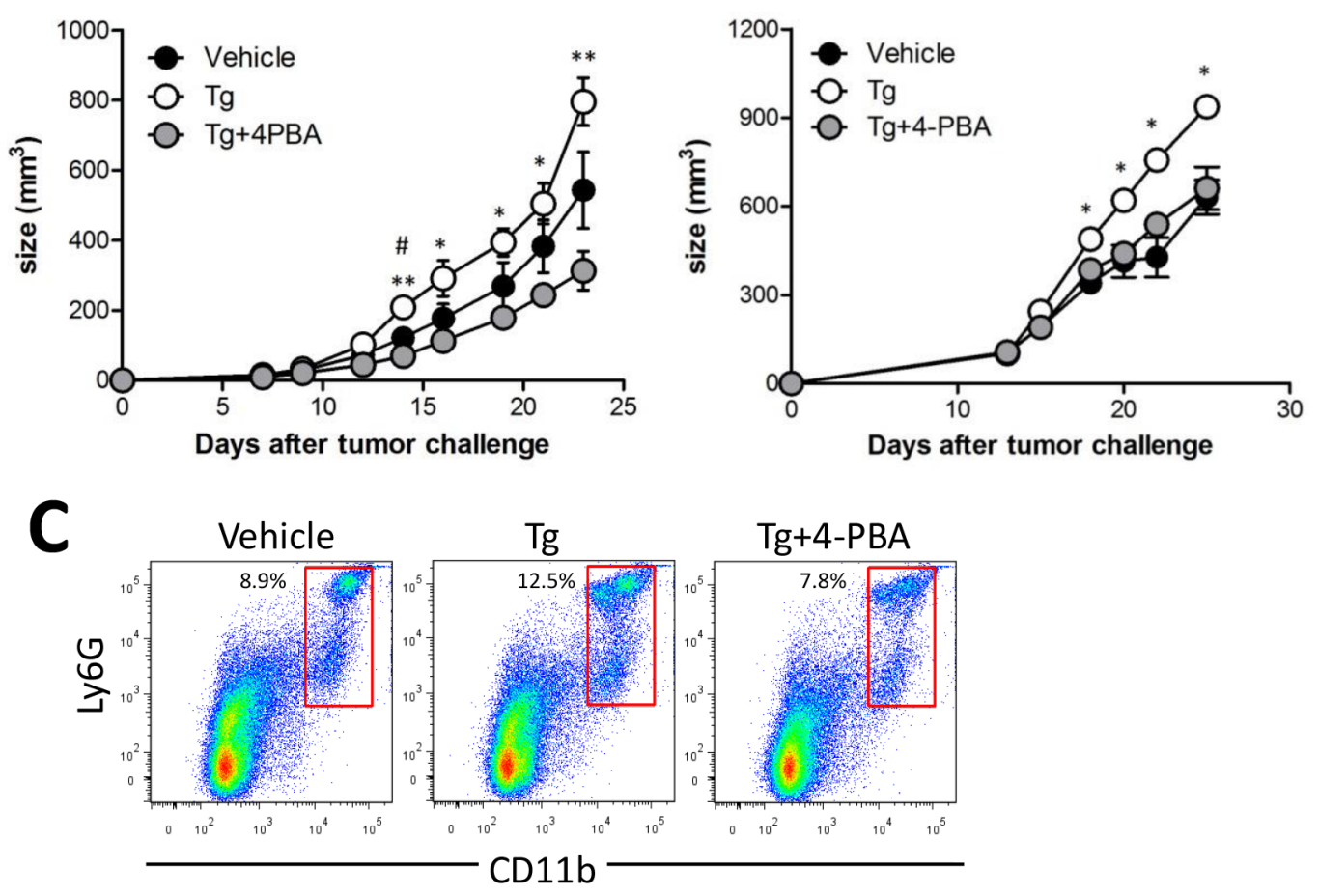

D
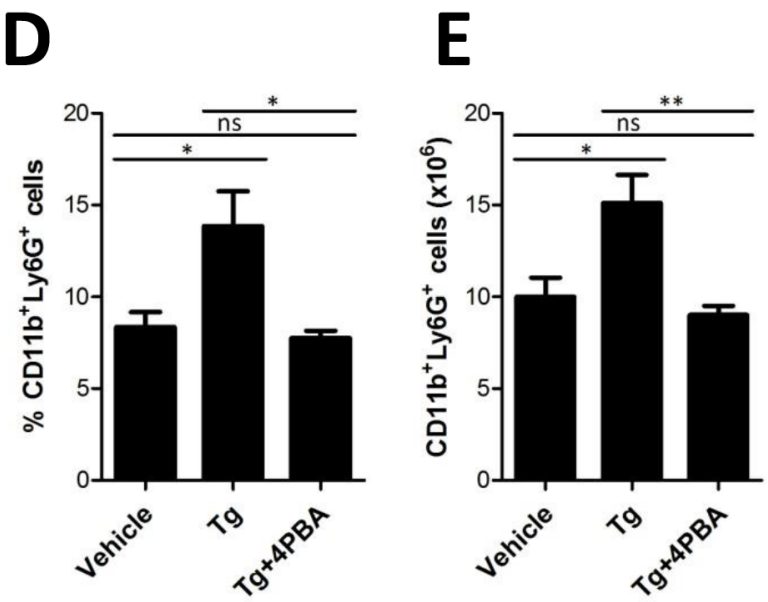

Figure 4: (4-PBA) attenuated Tg-induced MDSC expansion and tumor growth. (A) two weeks after HER2/CT26 tumor inoculation, $100 \mu \mathrm{g} / \mathrm{kg}$ Tg or $10 \mathrm{mg} / \mathrm{kg}$ 4-PBA was administered every day. Growth of HER2/CT26 tumors were measured $(n=6)$. ${ }^{*} p<0.05,{ }^{* *} p<0.01$ for Tg vs. Tg+4-PBA, ${ }^{*} p<0.05$ for vehicle vs. Tg, using one-way ANOVA. (B) two weeks after TC-1 tumor inoculation in C57BL/6 mice, $100 \mu \mathrm{g} / \mathrm{kg}$ Tg or $10 \mathrm{mg} / \mathrm{kg}$ 4-PBA was administered every day. Growth of TC-1 tumors were measured $(n=6) .{ }^{*} p<0.05$ using one-way ANOVA. (C) Ly $6 \mathrm{G}^{+} \mathrm{CD} 11 \mathrm{~b}^{+}$cells in the spleen of HER2/CT26 tumor-bearing mice treated with Tg and/or 4-PBA. (D and E) percentage and absolute number of Ly $6 \mathrm{G}^{+} \mathrm{CD} 11 \mathrm{~b}^{+}$MDSCs in the spleen of HER2/CT26 tumor-bearing mice treated with Tg and/or 4-PBA $(n=6)$. ns, not significant, ${ }^{*} p<0.05,{ }^{* *} p<0.01$ compared with matched control group using one-way ANOVA. 
$\mathrm{Ly}_{6 \mathrm{G}} \mathrm{CD} 11 \mathrm{~b}^{+} \mathrm{MDSC}$ in the spleen, and coadministration of 4-PBA significantly reduced the percentage and absolute number of $\mathrm{Ly}_{6 \mathrm{G}}^{+} \mathrm{CD} 11 \mathrm{~b}^{+} \mathrm{MDSCs}$, as compared with those of Tg-treated tumor-bearing mice (Figure 4C-E). However, in contrast to the results in splenic MDSCs, when tumor-infiltrating MDSCs were examined in tumorbearing mice, we found that neither the percentage nor the absolute number of $\mathrm{Ly} 6 \mathrm{G}^{+} \mathrm{MDSC}$ was increased (Supplementary Figures 3A-C). The subpopulation of CD $11 b^{+}$MDSCs, including Ly6G ${ }^{\text {high }}$ Ly6C ${ }^{\text {int }}$ and Ly6G ${ }^{\text {int }}$ Ly6C ${ }^{\text {high }}$ cells, showed a similar profile, except for an increased $\mathrm{Ly} 6 \mathrm{G}^{\text {high }} \mathrm{Ly} 6 \mathrm{C}^{\text {high }}$ population in the presence of ER stress (Supplementary Figure 3D-G). These results suggest that 4-PBA mitigates ER stress in the tumor microenvironment, leading to reduced tumor growth, and inhibits the expansion of splenic, but not tumorinfiltrating, $\mathrm{Ly}_{6 \mathrm{G}}^{+} \mathrm{CD} 11 \mathrm{~b}^{+} \mathrm{MDSCs}$.

\section{ER stress reinforced immunosuppressive function of MDSCs within tumor microenvironment}

MDSCs are known as tumor-associated suppressor cells and produce immunosuppression in opposition to various types of immune cells, including $\mathrm{CD}^{+} \mathrm{T}$ cell, $\mathrm{CD}^{+} \mathrm{T}$ cell, and NK cells $[15,16]$. Thus, we compared the suppressive function of MDSCs in the spleen and in the tumor tissue after Tg and/or 4-PBA treatment. MDSCs isolated from the spleen or from tumors were cocultured with OT-II peptide-pulsed splenic DCs and CFSE-labeled OT-II CD4 ${ }^{+} \mathrm{T}$ cells to determine $\mathrm{T}$ cell activation status. Despite the increased number of MDSCs in the spleen, we found no differences in the suppressive function of splenic MDSCs among vehicle, Tg, and Tg/4-PBA-treated mice (Figure 5A and 5B). In contrast, tumor-infiltrating MDSCs showed significantly increased immunosuppressive function after $\mathrm{Tg}$ treatment, as compared with vehicle treatment (Figure 5A and 5C). Treatment with 4-PBA significantly inhibited the suppressive function of tumor-infiltrating MDSCs under ER stress conditions (Figures 5A and 5C).

Several previous studies suggested that the immunosuppressive function of MDSCs was partly mediated by arginase-1 (ARG1) [17], iNOS [17], and reactive oxygen species (ROS) generated by NOX2 $[6,15,18]$. Therefore, we assessed the transcription levels of $A R G 1$, iNOS, and NOX2. Although there were no significant changes in the mRNA levels of $N O X 2$ and $A R G 1$ in splenic MDSCs among groups, the expression levels of $N O X 2, A R G 1$, and $i N O S$ were significantly increased in tumor-infiltrating MDSCs after Tg treatment, as compared with the vehicle control group (Figures 5D-I). Surprisingly, Tg-induced up-regulation of $A R G 1, N o x 2$, and $i N O S$ in tumor-infiltrating MDSCs was significantly inhibited by 4-PBA treatment (Figure 5G-I).
These results suggest that Tg-mediated ER stress enhances the immunosuppressive capacity of MDSCs at the local tumor site, which was mitigated by 4-PBA treatment.

\section{4-PBA restored anti-tumor immunity via dampening suppressive MDSCs exacerbated by ER stress}

Previously, we reported the conversion of immunosuppressive MDSCs into immunogenic Agpresenting cells (APCs) using activated invariant NKT cells, and that immunogenic APCs converted from MDSCs expressed significantly increased levels of costimulatory molecules, including CD40 and CD86 [5]. When we measured the expression of costimulatory molecules in MDSCs, CD40 and CD86 expression on splenic MDSCs was not changed by treatment with Tg or 4-PBA (Supplementary Figure 4).

To identify factors associated with the Tg-mediated increased immunosuppressive function of tumor-resident MDSCs, we first assessed levels of hypoxia inducible factors (HIFs), which have been shown to induce tumor angiogenesis and to be increased in the tumor microenvironment [19]. Increased levels of HIF $\alpha$ proteins activate PI3K-AKT-mTOR-STAT3 signaling [20] and thus could enhance the immunosuppressive function of MDSCs in tumors. We found that Tg-mediated ER stress induced expression of HIF transcription factors (Supplementary Figure 5). Tg-mediated increases in HIF-1 $\alpha$ and HIF-2 $\alpha$ in the tumor microenvironment were attenuated by 4-PBA.

In addition, NF- $\kappa \mathrm{B}$-dependent inflammatory cytokines such as IL-6, TNF- $\alpha$, and CXCL1/KC have been linked with the enhanced immunosuppressive activity of tumor-infiltrating MDSCs [14, 21]. Expression of these proinflammatory cytokines was enhanced by Tg-mediated ER stress, and this increased expression was attenuated by 4-PBA treatment (Figure 6A-C). Finally, we found that the abundance and activation status of tumor-infiltrating $\mathrm{CD}^{+} \mathrm{T}$ cells were restored by 4-PBA, which might be ascribable to attenuated suppressive capacity of MDSCs by reduced ER stress (Figure 6D-G). On the contrary, tumor-infiltrating $\mathrm{CD}^{+} \mathrm{T}$ cells showed no significant differences regardless of treatment. Taken together, these results show that 4-PBA restored anti-tumor immunity by dampening the ER stress-exacerbated suppressive capacity of MDSCs.

\section{DISCUSSION}

In the current study, ER stress induced by long-term Tg treatment of tumor-bearing mice accelerated tumor growth, as compared with that of vehicle-treated mice. Relief of ER stress by 4-PBA reduced the tumor growth to the level observed in non-treated mice. The tumor 


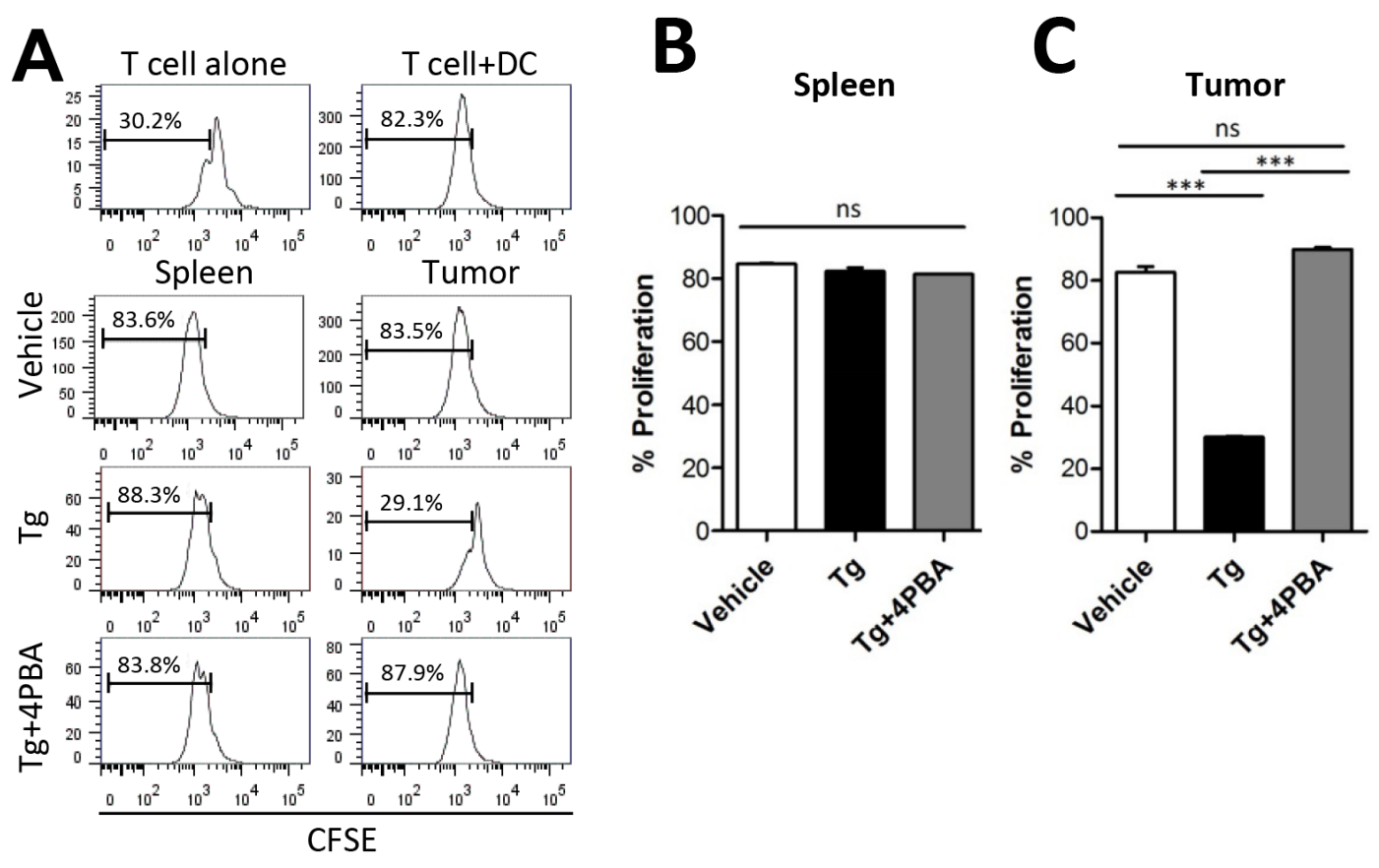

D

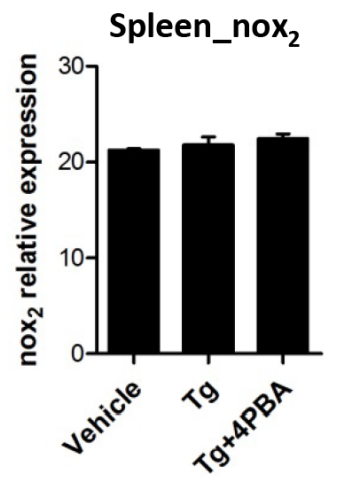

$\mathbf{G}$

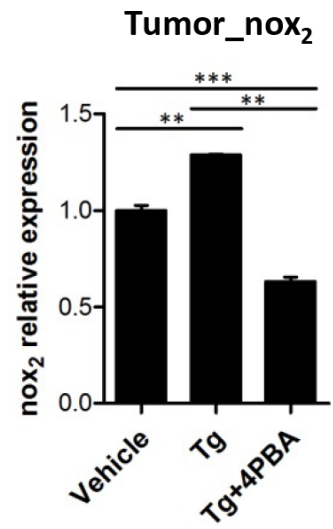

E

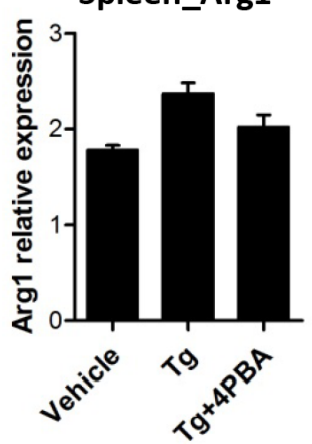

Tumor_Arg1

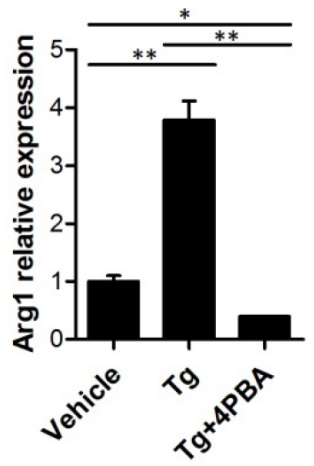

$\boldsymbol{F}$

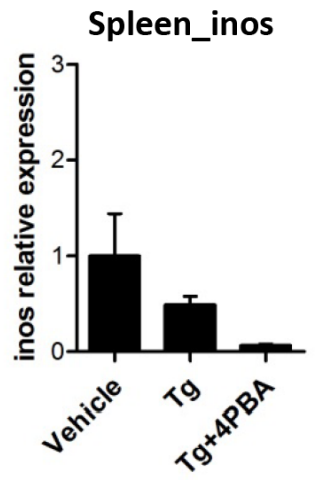

Tumor_inos

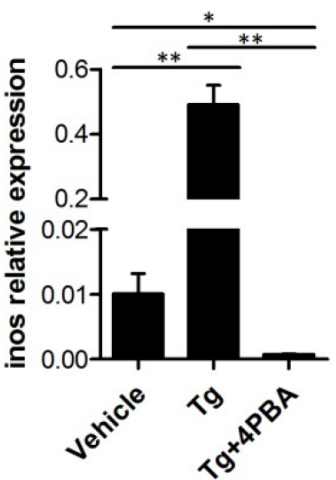

Figure 5: Tg-mediated ER stress reinforced the immunosuppressive capacity of tumor-infiltrating MDSCs. (A) MDSCs were isolated from the spleen or tumors of TC-1 tumor-bearing mice. OT-II peptide-pulsed splenic DCs and CFSE-labeled OT-II CD4 ${ }^{+}$ $\mathrm{T}$ cells were cocultured with MDSC for $72 \mathrm{~h}$. The percentages of proliferated OT-II CD4 $4^{+}$cells were determined via analysis of CFSE dilution. (B) proliferation of OT-II cells cocultured with spleen-infiltrating MDSCs $(n=3)$. (C) proliferation of OT-II cells cocultured with tumor-infiltrating MDSCs $(n=3)$. (D-F) mRNA levels of Nox2, Arg1, and iNOS in spleen-infiltrating MDSCs. (G-I) mRNA levels of Nox2, Argl, and iNOS in tumor-infiltrating MDSCs. ns, not significant, ${ }^{*} p<0.05,{ }^{* *} p<0.01,{ }^{* * *} p<0.001$ compared with matched control group using one-way ANOVA. 

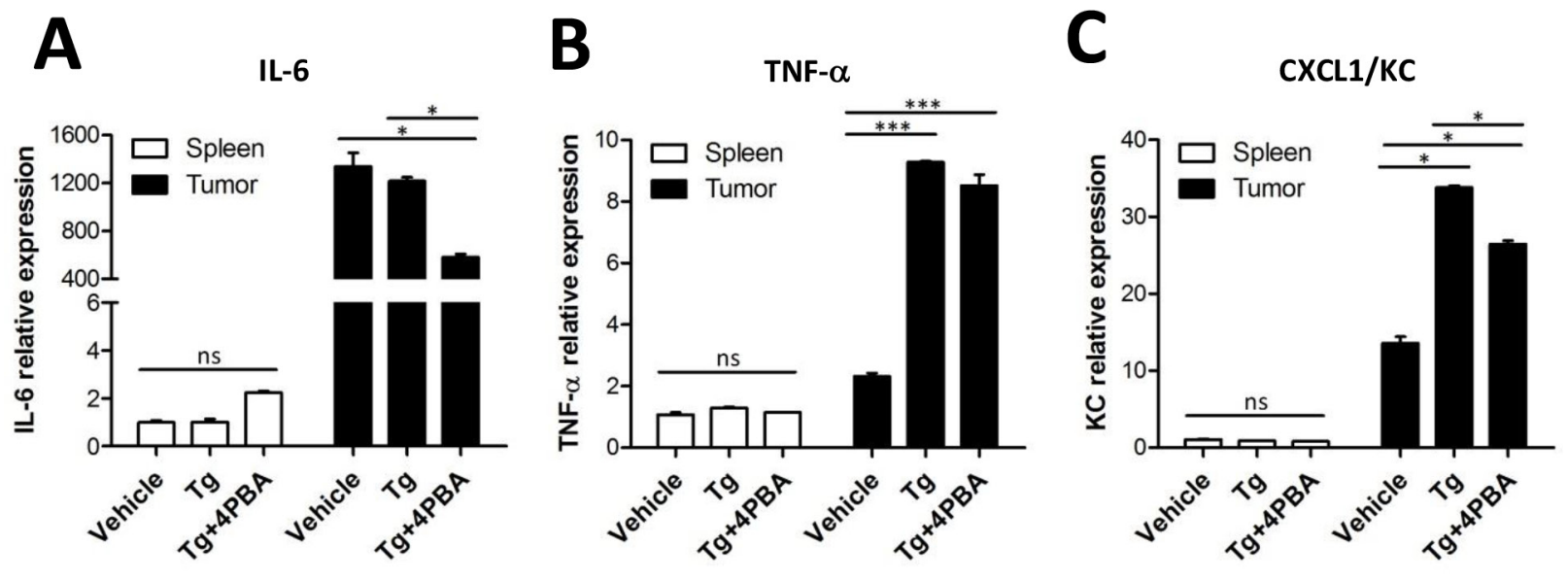

D Tumor infiltrating $\mathrm{CD}^{+} \mathrm{T}$ cells

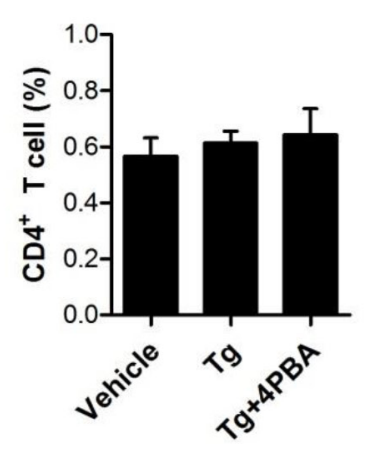

$\mathbf{F}$
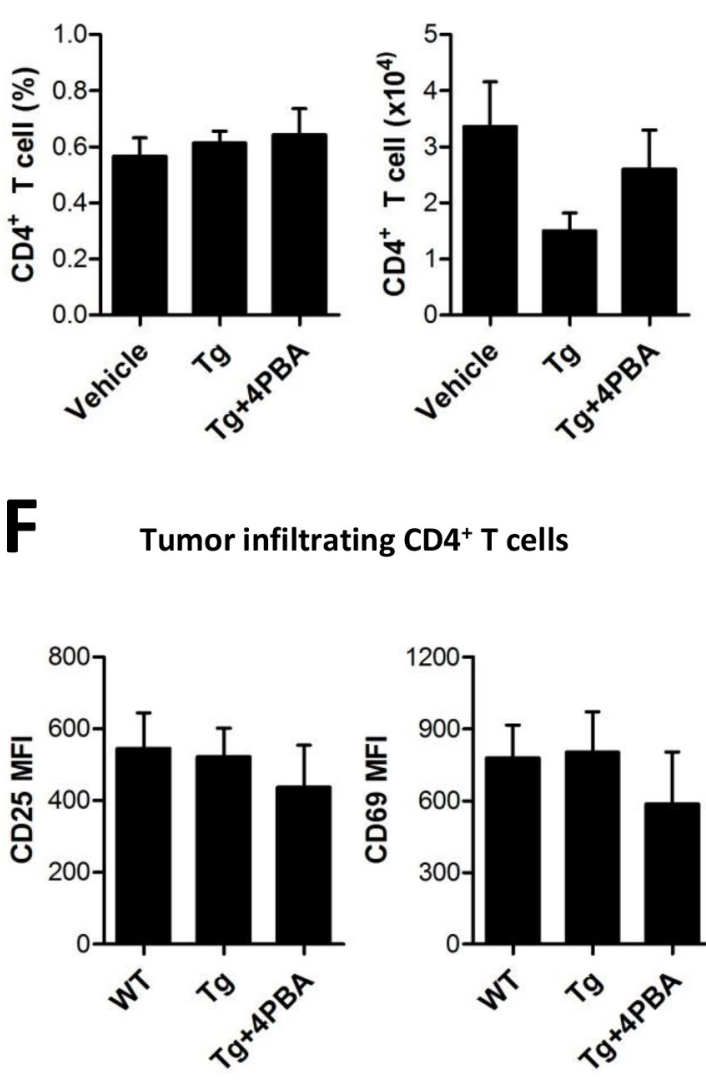

E
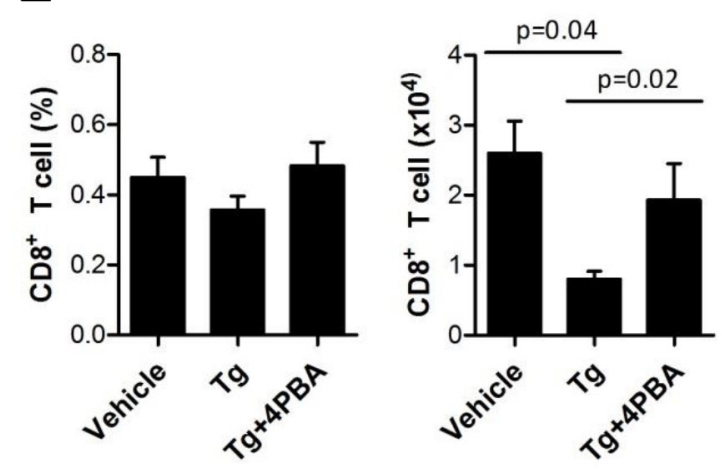

$\mathbf{G}$

Tumor infiltrating $\mathrm{CD8}^{+} \mathrm{T}$ cells

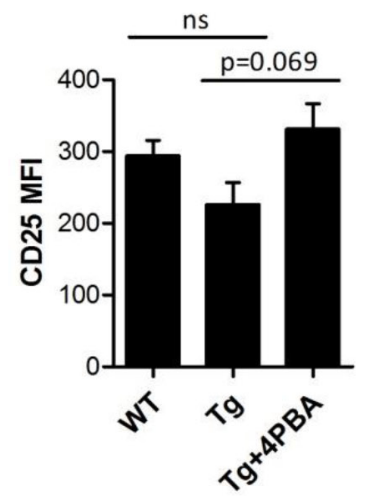

Figure 6: 4-PBA restored anti-tumor immunity via dampening of suppressive MDSCs exacerbated by ER stress. (A-C) mRNA levels of inflammatory cytokines (IL-6, TNF- $\alpha$, and KC) from spleen- or tumor-filtrating MDSCs. ns, not significant, ${ }^{*} p<0.05,{ }^{* * *} p<0.001$ using one-way ANOVA. (D) the percentage and absolute number of tumor-infiltrating $\mathrm{CD}^{+} \mathrm{T}$ cells $(n=3)$. (E) the percentage and absolute number of tumor-infiltrating CD8 ${ }^{+} \mathrm{T}$ cells $(n=3$, one-way ANOVA). (F) surface expression of activation markers CD25 and CD69 in tumor-infiltrating CD4 $4^{+} \mathrm{T}$ cells $(n=3)$. (G) surface expression of activation markers CD25 and CD69 in tumorinfiltrating $\mathrm{CD}^{+} \mathrm{T}$ cells $(n=3$, one-way ANOVA).

microenvironment leads to hypoxia, glucose and amino acid insufficiency, and ER biosynthesis malfunctioning $[14,22]$. Thus, there must be an elevation of ER stress and the unfolded protein response within tumor cells, and tumor-infiltrating cells, including MDSCs, might also be under ER stress. However, because 4-PBA alone could not induce tumor regression (Supplementary Figure 6), we concluded that tumor tissue may possess intrinsic mechanisms to cope with ER stress in hypoxic conditions, which mimic the effect of 4-PBA. 
How systemic ER stress affects MDSC in vivo? Enhanced ER stress by Tg treatment increased the number and the suppressive function of MDSCs whereas reduced ER stress by 4-PBA treatment significantly reduced them (Fig 4D-E and supplement Fig 3G). However, Tg treatment did not increase the proliferation of CT26 tumor cells in vitro (Fig 1F). Therefore, we expected that ER stress might be able to directly stimulate MDSCs expansion and enforce their suppressive activity. On the other hand, the larger tumor had more hypoxic condition inside the mass than smaller tumor, and consequently can influence on the further expansion of MDSCs in vivo. Our results showed that ER stress by $\mathrm{Tg}$ did not increase the proliferation of CT26 cells consistent with several other reports (Figure 1F). However, recent studies suggested that ER stress can induce GSK-3 $\beta$ activation [23], and their activation plays an important role in the proliferation of human ovarian and colorectal cancer cells [24, 25]. Therefore, we could not rule out the possibility that enhanced ER stress could make tumor growth faster, which could increase the proliferation and suppressive function of MDSCs.

The immunosuppressive function of MDSCs has been shown to be dependent on several mechanisms, such as arginine and cysteine metabolism and reactive oxygen species generation $[18,22]$. The expression of iNOS and ARG1 in MDSCs has been shown to be especially critical for the suppression of $\mathrm{T}$ cell function in an antigenindependent manner $[15,26]$. In addition, HIF-1 $\alpha$ induced under hypoxic conditions was involved in the up-regulation of iNOS and ARG1 in MDSCs [22]. HIF-1 $\alpha$ induced proangiogenic factors such as VEGFR1, PDGF-B, and angiopoietins, and HIF- $1 \alpha$ expression in MDSCs, was associated with immunosuppressive function and tumor progression [22, 27]. In contrast, splenic MDSCs, which have high levels of NOX2, increased production of reactive oxygen species, but failed to suppress antigen-independent $\mathrm{T}$ cell activation [22]. In addition, differences have been reported in the compositions of MDSC subsets in the spleen and in tumors [28, 29]. Granulocytic MDSCs in the spleen produce high levels of ROS via NOX2 [18], whereas up-regulated ARG1 and iNOS in tumor-infiltrating MDSCs was reported to be critical for their suppressive function [17]. In the current study, we found that the level of NOX2 was much higher in splenic MDSCs than in tumor-infiltrating MDSCs. However, levels of ARG1 and iNOS were significantly increased by Tg treatment in tumor-infiltrating MDSCs, but not in splenic MDSCs. These results suggest that the expression of ARG1 and iNOS in MDSCs is critical for their suppressive function, and could be increased by Tg-mediated ER stress under hypoxic conditions within tumor tissue, because in MDSCs their expression was correlated with immunosuppressive capacity against $\mathrm{CD}^{+} \mathrm{T}$ cells. Recently, we also showed that Myd88, an adaptor molecule critical for the activation of ARG1 and
NOX2 expression, was critical for the immunosuppressive function of MDSCs [6].

The induction of ER stress in cancer cells by oxaliplatin or anthracyclines has been shown to induce calreticulin (CRT) localization outside the cell membrane, which mediates immunogenic apoptosis to stimulate tumor-specific $\mathrm{CD}^{+} \mathrm{T}$ cell responses [30]. Tg treatment in mouse embryonic fibroblast (MEF) and neuroblastoma cells stimulated CRT cell surface exposure through ER $\mathrm{Ca}^{2+}$ depletion, and also promoted phagocytosis of apoptotic bodies [1]. However, we could not find any evidence of increased antitumor immune response caused by systemic administration of Tg. Instead, Tg treatment accelerated tumor growth as compared to vehicle treatment. Thus, ER $\mathrm{Ca}^{2+}$ depletion induced by Tg might not be sufficient to induce antigen presentation, even though phagocytosis of CRT-exposing apoptotic cancer cells was increased. To efficiently induce a tumor-specific $\mathrm{CD} 8^{+} \mathrm{T}$ cell response, an antigen needs to be presented by MHC class I molecules after phagocytosis [5]. However, this process could be hampered by multiple prerequisite steps for successful antigen presentation. Most importantly, lysosomal degradation must occur for antigen loading into the MHC class I pocket. Degradation of intracellular protein or organelles via lysosomal fusion during autophagy could increase lysosomal antigen degradation for MHC class I presentation [31]. Erp57, an ER-resident thiol disulfide oxidoreductase that forms a complex with CRT, was recently reported to modulate STAT3 signaling [32]. Because STAT3 activity is negatively regulated by Erp57 and dependent on the formation of Erp57-CRT complexes [32], Tg-induced ER stress might induce Erp57 malfunction by disassociating it with CRT. A further explanation for enhanced Tg-mediated tumor growth is its known function as a tumor promoter in certain circumstances via the Src-MAP kinase pathway [33], and PI-3 kinase-mediated activation of the serine/threonine protein kinase protein kinase $\mathrm{B}$ (PKB) by $\mathrm{Tg}$ treatment may enhance survival and proliferation of some cell types [34].

4-PBA has been used for the treatment of urea cycle disorders in children because of its function as an ammonia scavenger [35]. In addition, 4-PBA has also been studied as a potential treatment for several cancers, including human solid malignant tumors and recurrent malignant gliomas [36]. The inhibition of histone deacetylation by 4-PBA can repress gene expression, including that of genes related to tumor suppression, and represents an alternative treatment for cystic fibrosis [37]. The histone deacetylation inhibition activity of 4-PBA also resulted in decreased cancer proliferation [36]. More importantly, the chemical chaperone function of 4-PBA, which mimics intracellular protein chaperones and promotes protein folding in the ER, has been suggested as a means to treat pathological conditions related to several abnormal protein localization and aggregation disorders, such as Alzheimer's disease 
[38], amyotrophic lateral sclerosis [39], and lysosomal storage diseases. Indeed, recent studies showed that ER stress attenuation by 4-PBA restored glucose homeostasis in a mouse model of type 2 diabetes and alleviated colitis in mice [40, 41]. Although in this study we focused on the function of 4-PBA as a chemical chaperone to facilitate the correction of unfolded and misfolded proteins in the ER, tumor regression could be partially mediated by the inhibitory effect of 4-PBA on histone deacetylation [42]. Thus, the effect of butyrate on tumor growth after Tg treatment should be assessed, because it does not possess chemical chaperone activity, but can induce histone hyperacetylation by inhibiting histone deacetylation [43].

Several cytokines secreted by MDSCs inhibit the function of CTLs [44]. Accordingly, we found that Tg-mediated ER stress decreased the number and the activation of tumor-infiltrating $\mathrm{CD} 8^{+} \mathrm{T}$ cells, and 4-PBA treatment restored these parameters (Figure 6E and 6G) although the number and the activity of $\mathrm{CD}^{+} \mathrm{T}$ cell and $\mathrm{CD} 8^{+} \mathrm{T}$ cells in the spleen and lymph node were not affected by ER stress (Figure 2). Therefore, we suggest that ER stress reduction by 4-PBA treatment could overcome the immunosuppressive environment produced by MDSCs, particularly in tumors with excessive ER stress induced by $\mathrm{Tg}$ treatment, to restore anti-tumor immunity nearby tumor mass.

Recent studies showed that ER stress induced by $\mathrm{Tg}$ in prostate cancer cells up-regulated lipocalin 2 in an

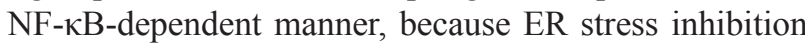
by 4-PBA and NF- $\mathrm{KB}$ inhibition by BAY11-7082 inhibited lipocalin 2 induction [16]. Thus, combination of 4-PBA with NF-kB inhibitors such as MG132 and BAY11-7082 might reduce ER stress-mediated tumor progression in our model. As another possible way to reduce ER stress, we and others have examined the consequences of activation of autophagy $[45,46]$. Autophagy, especially macroautophagy, is a lysosomal-dependent degradation pathway that removes unnecessary cytosolic proteins and organelles, and is activated, at least partly, for the resolution of ER stress [47]. Several methods of autophagy activation, including treatment with rapamycin, salubrinal, and $\alpha$-mangostin, represent candidates for ER stress reduction in cancer models via repression of the immunosuppressive function of MDSCs [45, 48, 49]. In addition, lithium chloride, a GSK-3 $\beta$ inhibitor, could attenuate Tg-mediated enhanced tumor growth, because Tg-induced apoptosis was prevented by GSK-3 $\beta$ inhibition [23].

Collectively, in our study, enhanced ER stress in tumor-bearing hosts increased tumor growth. Acceleration of tumor growth by ER stress was mediated by modulating the levels of ARG1 and iNOS in tumor-infiltrating MDSCs, which enhanced their immunosuppressive function. Therefore, ER stress reducers such as 4-PBA could restore anti-tumor immunity by dampening immunosuppressive MDSCs that are exacerbated by ER stress.

\section{MATERIALS AND METHODS}

\section{Mice}

All experiments were approved by the Institutional Animal Care and Use Committee of Kangwon National University. Wild-type BALB/c and C57BL/6 mice were purchased from Charles River Laboratories (Orient Bio Inc., Sungnam, Korea). OVA-specific OT-II (C57BL/6 background) TCR transgenic mice were purchased from Jackson Laboratories (Bar Harbor, ME). All mice used in the experiments were purchased at 6 weeks of age. The mice were kept in the Animal Center for Pharmaceutical Research at Kangwon National University. To establish tumors, mice were subcutaneously (s.c.) injected with $10^{6}$ tumor cells on the left flank.

\section{Cell line}

Human HER2/neu-expressing CT26 cells (hHER2/ CT26) $[4,5,50]$ and mouse TC-1 cervical cancer cells were used as tumor cells in these studies. To establish tumors, $10^{6}$ HER $2 / \mathrm{CT} 26$ or TC- 1 tumor cells were injected s.c. into the left flank of $\mathrm{BALB} / \mathrm{c}$ or $\mathrm{C} 57 \mathrm{BL} / 6$ mice, respectively. Tumor growth was measured by calipers 3 times per week.

\section{Reagents and antibodies}

Mice were treated with $100 \mu \mathrm{g} / \mathrm{kg} \mathrm{Tg}$ (Sigma-Aldrich, St. Louis, MO) and $10 \mathrm{mg} / \mathrm{kg}$ sodium 4-phenylbutyrate (Calbiochem, San Diego, CA) every day. All antibodies used for flow cytometry analysis were purchased from $\mathrm{BD}$ Biosciences (San Jose, CA).

\section{Isolation of tissue-infiltrating MDSCs}

To obtain tissue-infiltrating MDSCs, tumor tissue was gently homogenized with a MACS dissociator (Miltenyibiotec, Germany) and treated with $0.5 \mathrm{mg} / \mathrm{mL}$ collagenase type IV (Sigma-Aldrich, St. Louis, MO) for $30 \mathrm{~min}$. Cells were harvested by gentle pipetting and exposed to a $40-70 \%$ percoll gradient to enrich mononuclear cells. To isolate MDSCs, cells were treated with an anti$\mathrm{CD}_{11} \mathrm{~b}^{+}$microbead and isolated by MACS cell separation.

\section{Quantitative real-time PCR}

Total RNA was isolated from $10^{6}$ MDSCs using the RNA Extraction Mini Kit (iNtRON, Korea). Reverse transcription was performed using the cDNA Synthesis Mini Kit (iNtRON), and quantitative real-time polymerase chain reaction (PCR) was conducted using THUNDERBIRD ${ }^{\text {TM }}$ SYBR qPCR Mix (Toyobo, Japan). The following primers were used: 


\begin{tabular}{|c|c|c|}
\hline \multirow{2}{*}{ iNOS } & forward & 5'-AGGAAGTGGGCCGAAGGAT-3' \\
\hline & reverse & 5'-GAAACTATGGAGCACAGCCACAT-3' \\
\hline \multirow{2}{*}{ ARG1 } & forward & 5'-AACACGGCAGTGGCTTTAACCT-3' \\
\hline & reverse & 5'-GTGATGCCCCAGATGGTTTTC-3' \\
\hline \multirow{2}{*}{ Nox2 } & forward & 5'-GACCCAGATGCAGGAAAGGAA-3' \\
\hline & reverse & 5'-TCATGGTGCACAGCAAAGTGAT-3' \\
\hline \multirow{2}{*}{$\mathrm{BiP}$} & forward & 5'-ACTTGGGGACCACCTATTCCT-3' \\
\hline & reverse & 5'-ATCGCCAATCAGACGCTCC-3' \\
\hline \multirow{2}{*}{ ATF4 } & forward & 5'-ATGGCCGGCTATGGATGAT-3' \\
\hline & reverse & 5'-CGAAGTCAAACTCTTTCAGATCCATT-3' \\
\hline \multirow{2}{*}{ Chop } & forward & 5'-CTGGAAGCCTGGTATGAGGAT-3' \\
\hline & reverse & 5'-CAGGGTCAAGAGTAGTGAAGGT-3' \\
\hline \multirow{2}{*}{ Erdj4 } & forward & 5'-TCAGAGAGATTGCAGAAGCG-3' \\
\hline & reverse & 5'-GACTCCCATTGCCTCTTTGT-3' \\
\hline \multirow{2}{*}{ IL-6 } & forward & 5'- CTGGAGTCACAGAAGGAGTGG-3' \\
\hline & reverse & 5'- GGTTTGCCGAGTAGATCTCAA-3' \\
\hline \multirow{2}{*}{ CXCL1/KC } & forward & 5'- TGAGCTGCGCTGTCAGTGCC-3' \\
\hline & reverse & 5'- GCGTTCACCAGACGGTGCCA-3' \\
\hline \multirow{2}{*}{ TNF- $\alpha$} & forward & 5'- TGGGAGTAGACAAGGTACAACCC-3' \\
\hline & reverse & 5'- CATCTTCTCAAAATTCGAGTGACAA-3' \\
\hline \multirow{2}{*}{$\beta$-actin } & forward & 5'-CCTAGGCACCAGGGTGTGAT-3' \\
\hline & reverse & 5'-TCTCCATGTCGTCCCAGTTG-3' \\
\hline
\end{tabular}

\section{Western blot}

Total protein lysates from tumor cells or tissue were prepared by sonication in lysis buffer (iNtRON). Equal amounts of lysates were boiled at $100^{\circ} \mathrm{C}$ and resolved using $8-12 \%$ sodium dodecyl sulfate polyacrylamide gel electrophoresis (SDS-PAGE). Proteins were transferred to polyvinylidene difluoride (PVDF) membranes (Millipore, Billerica, MA, USA) that were blocked with $5 \%$ milk in tris-buffered saline and Tween 20 and incubated overnight with the primary antibody, and proteins were detected with an horseradish peroxidase (HRP)-conjugated antibody (Cell Signaling Technology). Membranes were developed by the enhanced chemiluminescence (ECL) method using femtoLUCENT ${ }^{\mathrm{TM}}$ PLUS-HRP (G-Biosciences, St. Louis, MO, USA)

\section{In vitro MDSC suppression}

OVA-specific TCR transgenic OT-II CD4 ${ }^{+} \mathrm{T}$ cells $\left(10^{5} /\right.$ well $)$ isolated from the spleens of OT-II mice were labeled with $1 \mu \mathrm{M}$ CFSE, stimulated with $\mathrm{H}-2^{\mathrm{b}}$-restricted OVA MHC class II epitope peptide (ISQAVHAAHAEINEAGR)-pulsed splenic DCs $\left(10^{3} /\right.$ well $)$, and cocultured with MDSCs $\left(2 \times 10^{5} /\right.$ well $)$ for $72 \mathrm{~h}$. CFSE dilutions of OT-II CD4 ${ }^{+} \mathrm{T}$ cells were analyzed using flow cytometry.

\section{In vivo cytotoxicity assay}

The in vivo cytotoxicity of $\mathrm{CD}^{+} \mathrm{T}$ cells was assessed as described previously $[6,51]$. Briefly, syngeneic splenocytes and lymph node (LN) cells were divided into 2 fractions of equal number that were either loaded with $1 \mu \mathrm{g} / \mathrm{mL}$ of cytotoxic $\mathrm{T}$ lymphocyte (CTL) epitope peptide (human HER2/neu p63 [TYLPTNASL]) or left unpulsed. Peptide-pulsed cells were labeled with $10 \mu \mathrm{M}$ CFSE (Invitrogen, Carlsbad, CA) and unpulsed cells were labeled with $1 \mu \mathrm{M}$ CFSE. Equal numbers of CFSE ${ }^{\text {high }}$ and $\mathrm{CFSE}^{\text {low }}$ cells were mixed and injected intravenously into mice. After $24 \mathrm{~h}$, the splenocytes from treated mice were analyzed to assess antigenic peptide-specific target lysis. The specific lysis was calculated as follows:

$$
\begin{aligned}
& \mathrm{r}(\text { ratio })=\left(\% C F S E^{\text {low }} / \% C F S E^{\text {high }}\right) \\
& \% \text { lysis }=\left(1-\left[r_{\text {unprimed }} / r_{\text {primed }}\right]\right) \times 100
\end{aligned}
$$




\section{Determination of cell viability}

Cell viability was determined using the Dojindo Cell Counting Kit-8 (Dojindo, Gaithersburg, MD, USA) according to the manufacturer's instructions. Splenocytes and tumor cells were seeded in 96-well plates and allowed to adhere overnight. The cells were treated with $\mathrm{Tg}$ at $37^{\circ} \mathrm{C}$ for $24 \mathrm{~h}$. The absorbance at $450 \mathrm{~nm}$ was measured with a SPECTRA MAX 340 instrument (Molecular Devices, US).

\section{Statistical analysis}

Student's t-test was used to compare differences between the 2 groups. To compare multiple groups, we performed one-way ANOVA followed by Tukey's post hoc test. Values of $p<0.05$ were considered to be significant.

\section{Funding}

This work was supported by a grant from the Korean Health Technology R\&D Project, Ministry of Health and Welfare, Republic of Korea (A120176).

\section{Conflict of interest}

The authors declare they have no conflicts of interest.

\section{REFERENCES}

1. Peters LR, Raghavan M. Endoplasmic reticulum calcium depletion impacts chaperone secretion, innate immunity, and phagocytic uptake of cells. J Immunol. 2011; 187:919-931.

2. Jackisch C, Hahm HA, Tombal B, McCloskey D, Butash K, Davidson NE, Denmeade SR. Delayed micromolar elevation in intracellular calcium precedes induction of apoptosis in thapsigargin-treated breast cancer cells. Clin Cancer Res. 2000; 6:2844-2850.

3. Dubois C, Vanden Abeele F, Sehgal P, Olesen C, Junker S, Christensen SB, Prevarskaya N, Moller JV. Differential effects of thapsigargin analogues on apoptosis of prostate cancer cells: complex regulation by intracellular calcium. FEBS J. 2013; 280:5430-5440.

4. Ko HJ, Kim YJ, Kim YS, Chang WS, Ko SY, Chang SY, Sakaguchi S, Kang CY. A combination of chemoimmunotherapies can efficiently break self-tolerance and induce antitumor immunity in a tolerogenic murine tumor model. Cancer Res. 2007; 67:7477-7486.

5. Ko HJ, Lee JM, Kim YJ, Kim YS, Lee KA, Kang CY. Immunosuppressive myeloid-derived suppressor cells can be converted into immunogenic APCs with the help of activated NKT cells: an alternative cell-based antitumor vaccine. J Immunol. 2009; 182:1818-1828.
6. Hong EH, Chang SY, Lee BR, Kim YS, Lee JM, Kang CY, Kweon MN, Ko HJ. Blockade of Myd88 signaling induces antitumor effects by skewing the immunosuppressive function of myeloid-derived suppressor cells. Int J Cancer. 2013; 132:2839-2848.

7. Chen CJ, Kono H, Golenbock D, Reed G, Akira S, Rock KL. Identification of a key pathway required for the sterile inflammatory response triggered by dying cells. Nat. Med. 2007; 13:851-856.

8. Malo A, Kruger B, Goke B, Kubisch CH. 4-Phenylbutyric acid reduces endoplasmic reticulum stress, trypsin activation, and acinar cell apoptosis while increasing secretion in rat pancreatic acini. Pancreas. 2013; 42:92-101.

9. Pyrko P, Kardosh A, Liu Y-T, Soriano N, Xiong W, Chow RH, Uddin J, Petasis NA, Mircheff AK, Farley RA, Louie SG, Chen TC, Schönthal AH. Calcium-activated endoplasmic reticulum stress as a major component of tumor cell death induced by 2,5-dimethyl-celecoxib, a non-coxib analogue of celecoxib. Mol. Cancer Ther. 2007; 6:1262-1275.

10. Thastrup O, Cullen PJ, Drobak BK, Hanley MR, Dawson AP. Thapsigargin, a tumor promoter, discharges intracellular $\mathrm{Ca} 2+$ stores by specific inhibition of the endoplasmic reticulum Ca2(+)-ATPase. P Natl Acad Sci USA. 1990; 87:2466-2470.

11. Denmeade SR, Jakobsen CM, Janssen S, Khan SR, Garrett ES, Lilja H, Christensen SB, Isaacs JT. ProstateSpecific Antigen-Activated Thapsigargin Prodrug as Targeted Therapy for Prostate Cancer. J Natl Cancer Inst. 2003; 95:990-1000.

12. Iwawaki T, Akai R, Kohno K, Miura M. A transgenic mouse model for monitoring endoplasmic reticulum stress. Nat Med. 2004; 10:98-102.

13. Kaiser AD, Gadiot J, Guislain A, Blank CU. Mimicking homeostatic proliferation in vitro generates $\mathrm{T}$ cells with high anti-tumor function in non-lymphopenic hosts. Cancer Immunol Immun. 2013; 62:503-515.

14. Mahadevan NR, Zanetti M. Tumor stress inside out: cellextrinsic effects of the unfolded protein response in tumor cells modulate the immunological landscape of the tumor microenvironment. J Immunol. 2011; 187:4403-4409.

15. Gabrilovich DI, Nagaraj S. Myeloid-derived suppressor cells as regulators of the immune system. Nat Rev Immunol. 2009; 9:162-174.

16. Bayne LJ, Vonderheide RH. A myeloid-derived suppressor cell-mediated T-cell suppression assay for functional evaluation of immune cells in tumor-bearing mice. Cold Spring Harb Protoc. 2013; 2013:849-853.

17. Lee J, Ryu H, Ferrante RJ, Morris SM, Jr., Ratan RR. Translational control of inducible nitric oxide synthase expression by arginine can explain the arginine paradox. P Natl Acad Sci USA. 2003; 100:4843-4848.

18. Corzo CA, Cotter MJ, Cheng P, Cheng F, Kusmartsev S, Sotomayor E, Padhya T, McCaffrey TV, McCaffrey JC, 
Gabrilovich DI. Mechanism regulating reactive oxygen species in tumor-induced myeloid-derived suppressor cells. J Immunol. 2009; 182:5693-5701.

19. Bi M, Naczki C, Koritzinsky M, Fels D, Blais J, Hu N, Harding H, Novoa I, Varia M, Raleigh J, Scheuner D, Kaufman RJ, Bell J, Ron D, Wouters BG, Koumenis C. ER stress-regulated translation increases tolerance to extreme hypoxia and promotes tumor growth. EMBO J. $2005 ; 24: 3470-3481$.

20. Werno C, Zhou J, Brüne B. A23187, ionomycin and thapsigargin upregulate mRNA of HIF- $1 \alpha$ via endoplasmic reticulum stress rather than a rise in intracellular calcium. J Cell Physiol. 2008; 215:708-714.

21. Bunt SK, Yang L, Sinha P, Clements VK, Leips J, Ostrand-Rosenberg S. Reduced inflammation in the tumor microenvironment delays the accumulation of myeloidderived suppressor cells and limits tumor progression. Cancer Res. 2007; 67:10019-10026.

22. Corzo CA, Condamine T, Lu L, Cotter MJ, Youn JI, Cheng P, Cho HI, Celis E, Quiceno DG, Padhya T, McCaffrey TV, McCaffrey JC, Gabrilovich DI. HIF-1alpha regulates function and differentiation of myeloid-derived suppressor cells in the tumor microenvironment. J Exp Med. 2010; 207:2439-2453.

23. Fu ZQ, Yang Y, Song J, Jiang Q, Lin ZC, Wang Q, Zhu LQ, Wang JZ, Tian Q. LiCl attenuates thapsigargin-induced tau hyperphosphorylation by inhibiting GSK-3beta in vivo and in vitro. J Alzheimers Dis. 2010; 21:1107-1117.

24. Li D. GSK-3beta as a driving force in ovarian cancer. Cell Res. 2006; 16:609.

25. Shakoori A, Ougolkov A, Yu ZW, Zhang B, Modarressi MH, Billadeau DD, Mai M, Takahashi Y, Minamoto T. Deregulated GSK3beta activity in colorectal cancer: its association with tumor cell survival and proliferation. Biochem Biophys Res Commun. 2005; 334:1365-1373.

26. Rodriguez PC, Hernandez CP, Quiceno D, Dubinett SM, Zabaleta J, Ochoa JB, Gilbert J, Ochoa AC. Arginase I in myeloid suppressor cells is induced by COX-2 in lung carcinoma. J Exp Med. 2005; 202:931-939.

27. Schmid MC, Varner JA. Myeloid cells in the tumor microenvironment: modulation of tumor angiogenesis and tumor inflammation. J Oncol. 2010; 2010:201026.

28. Movahedi K, Guilliams M, Van den Bossche J, Van den Bergh R, Gysemans C, Beschin A, De Baetselier P, Van Ginderachter JA. Identification of discrete tumorinduced myeloid-derived suppressor cell subpopulations with distinct $\mathrm{T}$ cell-suppressive activity. Blood. 2008; 111:4233-4244.

29. Youn JI, Nagaraj S, Collazo M, Gabrilovich DI. Subsets of myeloid-derived suppressor cells in tumor-bearing mice. J Immunol. 2008; 181:5791-5802.

30. Zitvogel L, Kepp O, Senovilla L, Menger L, Chaput N, Kroemer G. Immunogenic tumor cell death for optimal anticancer therapy: the calreticulin exposure pathway. Clin Cancer Res. 2010; 16:3100-3104.

31. Levine B, Mizushima N, Virgin HW. Autophagy in immunity and inflammation. Nature. 2011; 469:323-335.

32. Coe H, Jung J, Groenendyk J, Prins D, Michalak M. ERp57 modulates STAT3 signaling from the lumen of the endoplasmic reticulum. J Biol Chem. 2010; 285: 6725-6738.

33. Chao TS, Abe M, Hershenson MB, Gomes I, Rosner MR. Src tyrosine kinase mediates stimulation of Raf-1 and mitogen-activated protein kinase by the tumor promoter thapsigargin. Cancer Res. 1997; 57:3168-3173.

34. Huber M, Hughes MR, Krystal G. Thapsigargin-induced degranulation of mast cells is dependent on transient activation of phosphatidylinositol-3 kinase. J Immunol. 2000; 165:124-133.

35. Brusilow SW, Maestri NE. Urea cycle disorders: diagnosis, pathophysiology, and therapy. Adv Pediatr. 1996; 43:127-170.

36. Li LZ, Deng HX, Lou WZ, Sun XY, Song MW, Tao J, Xiao BX, Guo JM. Growth inhibitory effect of 4-phenyl butyric acid on human gastric cancer cells is associated with cell cycle arrest. World J Gastroentero. 2012; 18:79-83.

37. Kim DS, Li B, Rhew KY, Oh HW, Lim HD, Lee W, Chae HJ, Kim HR. The regulatory mechanism of 4-phenylbutyric acid against ER stress-induced autophagy in human gingival fibroblasts. Arch Pharm Res. 2012; 35:1269-1278.

38. Wiley JC, Meabon JS, Frankowski H, Smith EA, Schecterson LC, Bothwell M, Ladiges WC. Phenylbutyric acid rescues endoplasmic reticulum stress-induced suppression of APP proteolysis and prevents apoptosis in neuronal cells. PloS one. 2010; 5:e9135.

39. Petri S, Kiaei M, Kipiani K, Chen J, Calingasan NY, Crow JP, Beal MF. Additive neuroprotective effects of a histone deacetylase inhibitor and a catalytic antioxidant in a transgenic mouse model of amyotrophic lateral sclerosis. Neurobiol Dis. 2006; 22:40-49.

40. Ozcan U, Yilmaz E, Ozcan L, Furuhashi M, Vaillancourt E, Smith RO, Gorgun CZ, Hotamisligil GS. Chemical chaperones reduce ER stress and restore glucose homeostasis in a mouse model of type 2 diabetes. Science. 2006; 313:1137-1140.

41. Cao SS, Zimmermann EM, Chuang BM, Song B, Nwokoye A, Wilkinson JE, Eaton KA, Kaufman RJ. The unfolded protein response and chemical chaperones reduce protein misfolding and colitis in mice. Gastroenterology. 2013; 144:989-1000.e1006.

42. West AC, Mattarollo SR, Shortt J, Cluse LA, Christiansen AJ, Smyth MJ, Johnstone RW. An intact immune system is required for the anticancer activities of histone deacetylase inhibitors. Cancer Res. 2013; 73:7265-7276. 
43. Kubota K, Niinuma Y, Kaneko M, Okuma Y, Sugai M, Omura T, Uesugi M, Uehara T, Hosoi T, Nomura Y. Suppressive effects of 4-phenylbutyrate on the aggregation of Pael receptors and endoplasmic reticulum stress. J Neurochem. 2006; 97:1259-1268.

44. Goedegebuure P, Mitchem JB, Porembka MR, Tan MC, Belt BA, Wang-Gillam A, Gillanders WE, Hawkins WG, Linehan DC. Myeloid-derived suppressor cells: general characteristics and relevance to clinical management of pancreatic cancer. Curr Cancer Drug Tar. 2011; 11:734-751.

45. Kim SJ, Hong EH, Lee BR, Park MH, Kim JW, Pyun AR, Kim YJ, Chang SY, Chin YW, Ko HJ. alpha-Mangostin Reduced ER Stress-mediated Tumor Growth through Autophagy Activation. Immune netw. 2012; 12:253-260.

46. Bachar-Wikstrom E, Wikstrom JD, Ariav Y, Tirosh B, Kaiser N, Cerasi E, Leibowitz G. Stimulation of autophagy improves endoplasmic reticulum stress-induced diabetes. Diabetes. 2013; 62:1227-1237.

47. Rabinowitz JD, White E. Autophagy and metabolism. Science. 2010; 330:1344-1348.
48. Salazar M, Carracedo A, Salanueva IJ, Hernandez-Tiedra S, Lorente M, Egia A, Vazquez P, Blazquez C, Torres S, Garcia S, Nowak J, Fimia GM, Piacentini M, Cecconi F, Pandolfi PP, Gonzalez-Feria L, et al. Cannabinoid action induces autophagy-mediated cell death through stimulation of ER stress in human glioma cells. J Clin Invest. 2009; 119:1359-1372.

49. Ciechomska IA, Kaminska B. ER stress and autophagy contribute to CsA-induced death of malignant glioma cells. Autophagy. 2012; 8:1526-1528.

50. Chang SY, Lee KC, Ko SY, Ko HJ, Kang CY. Enhanced efficacy of DNA vaccination against Her-2/neu tumor antigen by genetic adjuvants. Int J Cancer. 2004; 111:86-95.

51. Kim YS, Kim YJ, Lee JM, Han SH, Ko HJ, Park HJ, Pereboev A, Nguyen HH, Kang CY. CD40-targeted recombinant adenovirus significantly enhances the efficacy of antitumor vaccines based on dendritic cells and B cells. Hum Gene Ther. 2010; 21:1697-1706. 